\title{
Schooling and Public Capital in a Model of Endogenous Growth
}

\author{
Pierre-Richard Agénor* \\ Hallsworth Professor of International Macroeconomics \\ and Development Economics \\ University of Manchester, United Kingdom \\ and Centre for Growth and Business Cycle Research
}

First complete draft: June 21, 2005

This version: January 11, 2006

\begin{abstract}
This paper studies the allocation of public spending between education services and infrastructure investment in an endogenous growth model where public capital in infrastructure affects the process of human capital accumulation. The balanced growth path is derived and the dynamics associated with a budget-neutral reallocation of spending from education to infrastructure are studied through numerical simulations. The growth-maximizing tax rate is shown to depend only on the production technology (as in standard flow models of public expenditure), whereas the optimal share of infrastructure investment depends also on the "productiveness" of infrastructure (relative to education services) in the schooling technology.
\end{abstract}

JEL Classification Numbers: H54, I28, O41.

*I am grateful to Nihal Bayraktar for assistance in preparing the numerical simulations reported in this paper, and to Kyriakos Neanidis for helpful discussions and comments. The views expressed here, however, are my own. 


\section{Contents}

1 Introduction 3

2 The Economy $\quad 6$

2.1 Production of Goods . . . . . . . . . . . . . . . . 6

2.2 Household Optimization . . . . . . . . . . . . . . . 7

2.3 Production of Educated Labor . . . . . . . . . . . . . . . 8

2.4 Government . . . . . . . . . . . . . . . . . . 10

3 The Balanced Growth Path 11

4 Dynamics of Expenditure Shift 12

4.1 Calibration ..................... 14

4.2 Policy Experiment . . . . . . . . . . . . . . . . . . . 19

5 Growth-Maximizing Policies $\quad 22$

6 Concluding Remarks $\quad 26$

$\begin{array}{lr}\text { Appendix } & 30\end{array}$

$\begin{array}{ll}\text { References } & 34\end{array}$

Figure 1: Shift in Spending from Education to Infrastructure 37 


\section{Introduction}

Much of the current international debate on ways to spur growth, reduce poverty, and improve the quality of human life in low-income developing countries has focused on the need for a large increase in public investment in infrastructure (see, for instance, United Nations Millennium Project (2005)). In contrast to the early literature on the design of adjustment programswhich often viewed public expenditure only through its impact on fiscal deficits and mostly, therefore, as an instrument of short-run macroeconomic adjustment - the current perspective has emphasized the supply-side effects of public investment and their implications for private capital accumulation and growth in per capita income.

The growth effects of public spending have also received much attention in the analytical literature on endogenous growth. As shown in an early contribution by Barro (1990) and much of the subsequent literature spawn by it, public services and capital in infrastructure may have a growth-promoting effect (through their effect on the productivity of factors and the rate of return on capital), and the growth-maximizing rates of taxation and public investment are in general positive. Moreover, this literature has also clarified some of the potential trade-offs that may arise, in designing growth-maximizing policies, between investment in infrastructure and other components of public spending - such as subsidies to private capital accumulation, maintenance expenditure, and the provision of education or utility-enhancing services.

This paper contributes to the existing literature on public investment and growth in several ways. It develops an endogenous growth model with human capital accumulation and external effects associated with public capital in infrastructure, and examines the optimal determination of the tax rate 
and the shares of tax revenue allocated to public infrastructure investment and education services. As for instance in Futagami, Morita, and Shibata, (1993), Glomm and Ravikumar (1994), Fisher and Turnovsky (1998), Baier and Glomm (2001), Turnovsky (1997, 2000), and Gómez (2004), public infrastructure is treated as a stock. ${ }^{1}$ Unlike Lucas-type models, however, education is in principle compulsory, and knowledge is embodied in workers. These assumptions are more appropriate for low-income developing countries where, as documented by UNESCO (2004), schooling is compulsory not only at the primary level but also in part at the secondary level as well, and one of the key policy issues is to provide basic skills to a largely illiterate labor force. However, I assume that there is excess demand for skills, and this leads the government (to avoid overcrowded classrooms) to ration access to schools. To capture the idea that skills are essential to the production process, I also assume that the economy's technology is such that only educated workers can be used in the production of goods or the provision of education.

A crucial feature of the model is that the production of educated labor requires not only teachers and public spending on education services, but also access to infrastructure capital. As documented by Brenneman and Kerf (2002), many recent microeconomic studies have found a positive impact of infrastructure services on educational attainment, possibly through an indirect improvement in health indicators. A better transportation system and a safer road network (particularly in rural areas) help to raise school attendance. Greater access to safe water and sanitation enhance the health of individuals, increasing their ability to learn. Electricity allows more time

\footnotetext{
${ }^{1}$ Glomm and Ravikumar (1994) assume that private and public capital depreciate fully each period. Given constant returns to scale in production, the economy is thus always on a balanced growth path. In contrast, in the present setting, transitional dynamics are explicitly analyzed.
} 
to study and more opportunities to use electronic equipment and devices that may improve the learning process. In quantitative terms, the difference that infrastructure makes can be sizable. For instance, in the late 1990s in Nicaragua, 72 percent of children living in a household with electricity were attending school, compared to only 50 percent for those living in a household without electricity (see Saghir (2005)). As far as I know, this paper is the first to account explicitly for these effects in a model where public infrastructure is treated as a stock. ${ }^{2}$

The paper is organized as follows. The model is presented in Section II, and its balanced growth path is derived in Section III. Given the complexity of the model, section IV uses numerical techniques to examine the transitional and long-run effects of a switch in government spending from education to infrastructure, for different values of the parameters characterizing the schooling technology. The key issue here is whether reallocating funds from education to infrastructure can increase the growth rate, given that public infrastructure capital affects the production of educated labor. Section V determines the optimal (growth-maximizing) shares of government spending on infrastructure investment and education services. As shown by Barro (1990), if public infrastructure services derive from flow expenditures, the optimal rate of spending (or, equivalently, taxation in his setting) is equal to the elasticity of output with respect to these services. A similar result obtains when the flow of services is produced by the stock of public capital (see Futagami, Morita and Shibata (1993)), or when it is produced by a stock-flow combination (see Tsoukis and Miller (2003)), in the absence of maintenance

\footnotetext{
${ }^{2}$ In a previous paper (see Agénor (2005b)), I considered the case where the flow of government services in infrastructure affect the economy's ability to produce educated labor. The optimal rules derived in that paper will later be compared with those obtained here with a stock treatment.
} 
costs. $^{3}$ Here I examine how the optimal allocation differs from the Barro rule, and more specifically how it depends on the fact that public capital in infrastructure affects the education technology. The final section summarizes the main results of the paper and offers some concluding remarks.

\section{The Economy}

Consider an economy populated by a single, infinitely-lived household who produces and consumes a homogenous good, which can be used for consumption or investment. The good is traded on world markets; its price is therefore fixed and normalized to unity for simplicity. Raw (or uneducated) labor grows at a constant rate and must be educated to be used in the production of goods and the transmission of skills. The government invests in infrastructure (roads, telecommunications, electricity, water and sanitation, and so forth) and provides education services (such as books and other training materials). It balances its budget continuously, by levying a flat tax on output.

\subsection{Production of Goods}

Output, $Y$, is produced with private physical capital, $K_{P}$, public infrastructure capital, $K_{G}$, and educated labor, $E$, using a Cobb-Douglas technology: ${ }^{4}$

$$
Y=K_{G}^{\alpha}(\chi E)^{\beta} K_{P}^{1-\alpha-\beta},
$$

where $\chi \in(0,1)$ is the proportion of the educated labor force employed in private production, and $\alpha, \beta \in(0,1)$. Thus, production exhibits constant

\footnotetext{
${ }^{3}$ As shown by Turnovsky (1996), however, if private investment is subject to adjustment costs that fall with public services, the positive impact of government spending on growth will be more pronounced. The Barro rule would then underestimate the optimal tax rate.

${ }^{4}$ The time subscript $t$ is omitted whenever there is no risk of confusion. A dot over a variable is used later on to denote the derivative of that variable with respect to time.
} 
returns to scale in all factors (which are all augmentable), with diminishing returns with respect to each of them. Evidence supporting the assumption of constant returns to scale in labor, public capital, and private capital is provided in a variety of studies, including Otto and Vos (1998), and Song $(2002) .^{5}$

Public services in infrastructure are for simplicity assumed to be directly proportional to public capital, which is non-rival and non-excludable; extending the analysis to account for both public capital and public services as separate production inputs (as in Ghosh and Roy (2004), for instance), is straightforward. Similarly, $K_{P}$ denotes both the stock of private capital and the flow of services that this capital produces.

\subsection{Household Optimization}

Assuming no disutility associated with working, no government-provided utility-enhancing services, and no utility per se from becoming educated, the household maximizes the discounted stream of future utility

$$
\max _{C} U=\int_{0}^{\infty} \ln C \exp (-\rho t) d t
$$

where $C$ is consumption and $\rho$ the discount rate.

Capital does not depreciate. The household's budget constraint is

$$
C+\dot{K}_{P}=(1-\tau) Y+(1-\chi) w_{G} E,
$$

where $\tau \in(0,1)$ is the tax rate on output, $(1-\chi) E$ the number of educated workers employed as public sector teachers, and $w_{G}$ the wage earned by these workers.

\footnotetext{
${ }^{5}$ See also Eicher and Turnovsky (1999) for a discussion of the importance of the CobbDouglas specification to ensure constant per capita growth rates in endogenous growth models.
} 
The household takes public policies as given when choosing the optimal sequence of consumption. Maximizing (2) subject to (1) and (3) yields the familiar first-order necessary condition

$$
\frac{\dot{C}}{C}=s \chi^{\beta}\left(\frac{K_{G}}{K_{P}}\right)^{\alpha}\left(\frac{E}{K_{P}}\right)^{\beta}-\rho .
$$

together with the transversality condition

$$
\lim _{t \rightarrow \infty} \lambda K_{P}(t) \exp (-\rho t)=0
$$

where $s \equiv(1-\tau)(1-\alpha-\beta)$, so that $s \in(0,1)$.

\subsection{Production of Educated Labor}

The economy's raw labor endowment must be educated to become productive. The schooling technology is specified as a Cobb-Douglas function of government spending on education, $G_{E}$, public capital in infrastructure, $K_{G}$, the number of students, $L$, and the number of teachers, $(1-\chi) E$, to produce the flow of newly-educated workers. Assuming no depreciation of skills, the flow supply of educated labor, $\dot{E}$, can be written as

$$
\dot{E}=G_{E}^{\kappa_{1}} K_{G}^{\kappa_{2}} L^{\kappa_{3}}[(1-\chi) E]^{1-\Sigma \kappa_{h}},
$$

where $\kappa_{h} \in(0,1)$ for $h=1,2,3$. The schooling technology exhibits therefore constant returns to scale in all inputs. To rule out the case where the number of newly-educated workers exceeds the number of students, I assume that $L$ is large enough to ensure that $\dot{E}<L$.

Equation (6) can also be written as

$$
\dot{E}=(1-\chi)^{1-\Sigma \kappa_{h}}\left(\frac{G_{E}}{E}\right)^{\kappa_{1}}\left(\frac{K_{G}}{E}\right)^{\kappa_{2}}\left(\frac{L}{E}\right)^{\kappa_{3}} E .
$$

Let $n$ denote the rate at which the population of students (taken from the raw labor force) grows. Given that the stock of educated labor grows at 
a constant rate $\gamma$ in the steady state (as shown below), the restriction $\gamma \leq n$ must hold. Put differently, given that in the present setting knowledge is embodied in workers, in the long run the economy cannot produce educated workers at a rate greater than the rate at which "illiterate" individuals enter the schooling system.

A simple way to impose this restriction is to assume that the government's policy for admitting students in the education system is such that it keeps the ratio of teachers to students constant, in order to maintain the quality of schooling:

$$
\frac{L}{(1-\chi) E}=a>0
$$

This rule implies that, in the steady state, $n=\gamma \cdot{ }^{6}$ Thus, education is not a pure public good; it is non-excludable (an uneducated individual cannot prevent others in the same situation from accessing the education services that the government provides free of charge), but it is rival beyond a certain point (the use of the education system by a sufficient number of uneducated individuals precludes its use by others, given rule (8)).

Given (8), equation (7) can be rewritten as

$$
\frac{\dot{E}}{E}=A_{E}\left(\frac{G_{E}}{E}\right)^{\kappa_{1}}\left(\frac{K_{G}}{E}\right)^{\kappa_{2}},
$$

where $A_{E} \equiv a^{\kappa_{3}}(1-\chi)^{1-\kappa_{1}-\kappa_{2}}$. Thus, unless $\kappa_{2}=0$, the growth rate of educated labor depends on the ratio of public infrastructure capital to educated labor.

\footnotetext{
${ }^{6}$ The growth rate of the total population of raw labor (which is exogenous) must therefore be at least equal to $n$.
} 


\subsection{Government}

The government collects a proportional tax $\tau$ on output. It invests in infrastructure capital, $G_{I}$, pays salaries to teachers in public schools, and provides education services that are used in the production of educated labor. Thus, the government budget constraint is given by ${ }^{7}$

$$
\left(G_{E}+G_{I}\right)+(1-\chi) w_{G} E=\tau Y .
$$

From (3) and (10), the economy's consolidated budget constraint (or equivalently, the goods market equilibrium condition) is

$$
C+\dot{K}_{P}+\left(G_{E}+G_{I}\right)=Y .
$$

Both education services and investment in infrastructure are constant fractions of tax revenues, $v_{E}$ and $v_{I}$, with $v_{E}, v_{I} \in(0,1)$ :

$$
G_{h}=v_{h} \tau Y, \quad h=E, I .
$$

Using these definitions, the government budget constraint can be rewritten as

$$
(1-\chi) w_{G} E=\left(1-v_{E}-v_{I}\right) \tau Y
$$

or equivalently, assuming that wages are a fraction $\varphi \in(0,1)$ of tax revenues,

$$
v_{E}+v_{I}=1-\varphi
$$

Assuming also no physical depreciation, the stock of public capital in infrastructure evolves over time according to ${ }^{8}$

$$
\dot{K}_{G}=G_{I} .
$$

\footnotetext{
${ }^{7}$ For simplicity, teachers' income is asssumed not to be taxed. Given that the household takes salaries as given in solving its optimization problem, assuming the contrary would make no difference for the law of motion of consumption. It would not have any effect either on the law of motion of private capital, which is derived from the economy's consolidated budget constraint.

${ }^{8}$ See Agénor $(2005 c)$ for a discussion of the case where the depreciation rate of public capital is endogenous, albeit in a model with no public education.
} 


\section{The Balanced Growth Path}

As shown in the Appendix, the dynamics of the economy are driven by a set of three nonlinear differential equations in $c=C / K_{P}, k_{G}=K_{G} / K_{P}$, and $e=E / K_{P}:$

$$
\begin{gathered}
\frac{\dot{c}}{c}=\Omega \chi^{\beta} k_{G}^{\alpha} e^{\beta}+c-\rho, \\
\frac{\dot{e}}{e}=A_{E} \chi^{\beta \kappa_{1}}\left(\tau v_{E}\right)^{\kappa_{1}} k_{G}^{\theta_{1}} e^{-\theta_{2}}-\mu \chi^{\beta} k_{G}^{\alpha} e^{\beta}+c, \\
\frac{\dot{k}_{G}}{k_{G}}=\left(\frac{\tau v_{I}}{k_{G}}-\mu\right) \chi^{\beta} k_{G}^{\alpha} e^{\beta}+c,
\end{gathered}
$$

where

$$
\begin{gathered}
\Omega \equiv s-\mu<0, \quad \mu \equiv 1-\tau(1-\varphi)>0, \\
\theta_{1} \equiv \alpha \kappa_{1}+\kappa_{2}>0, \quad \theta_{2} \equiv(1-\beta) \kappa_{1}+\kappa_{2}>0 .
\end{gathered}
$$

These equations, together with the initial conditions $e_{0}=E_{0} / K_{G, 0}>0$, and $k_{G, 0}=K_{G, 0} / K_{P, 0}>0$, and the transversality condition (5), rewritten as

$$
\lim _{t \rightarrow \infty} c_{t}^{-1} \exp (-\rho t)=0,
$$

characterize the dynamics of the economy. The long-run (or steady-growth) equilibrium corresponds to a set of functions $\left\{c, e, k_{G}\right\}_{t=0}^{\infty}$ such that equations (15), (16), and (17), the budget constraint (13), and the transversality condition (18) are satisfied, and consumption, the stock of educated labor, and the stocks of public and private capital, all grow at the same constant rate, that is, $\dot{C} / C=\dot{E} / E=\dot{K}_{P} / K_{P}=\dot{K}_{G} / K_{G}=\gamma$. This is also the rate of growth of output, given the assumption of constant returns to scale.

From equations (A2), (A4), and (A5) in the Appendix, the steady-state growth rate $\gamma$ is given by the equivalent forms ${ }^{9}$

$$
\gamma=s \chi^{\beta} \tilde{k}_{G}^{\alpha} \tilde{e}^{\beta}-\rho,
$$

\footnotetext{
${ }^{9}$ From (A1) in the Appendix, there is a fourth equivalent form, $\gamma=[1-\tau(1-$ $\varphi)] \chi^{\beta} \tilde{k}_{G}^{\alpha} \tilde{e}^{\beta}-\tilde{c}$. However, given (A12), this expression is identical to (19).
} 


$$
\begin{gathered}
\gamma=A_{E} \chi^{\beta \kappa_{1}}\left(\tau v_{E}\right)^{\kappa_{1}} \tilde{k}_{G}^{\theta_{1}} \tilde{e}^{-\theta_{2}}, \\
\gamma=\tau v_{I} \chi^{\beta} \tilde{k}_{G}^{\alpha-1} \tilde{e}^{\beta},
\end{gathered}
$$

where $\tilde{e}, \tilde{k}_{G}$ denote the steady-state values of $e$ and $k_{G}$.

The steady-growth equilibrium is unique if the following conditions are satisfied. First, the growth rate must be positive. From (19), this is guaranteed as long as the rate of time preference is not too large. Second, the utility integral in $(2)$ must converge $\left(\int_{0}^{\infty} \ln C \exp (-\rho t) d t<\infty\right)$. This is indeed the case here. Third, the transversality condition (18) must be satisfied. Because consumption and the stock of private capital grow at the same constant rate along any equilibrium path with $\gamma>0$, the ratio $c=C / K_{P}$ is indeed constant. Finally, the steady-state value of the consumption-private capital ratio must be positive for the solution to be feasible $(\tilde{c}>0)$. As shown in the Appendix, this condition always holds.

As also shown in the Appendix, saddlepath stability (even in the vicinity of the balanced-growth path) cannot be fully established analytically. The model may therefore be locally indeterminate, for some configurations of the parameters. Nevertheless, I will proceed under the assumption that the conditions for saddlepath stability identified in the Appendix are satisfied. The numerical simulations performed in the next section, using plausible values for the parameters, suggest indeed that this may not be an unreasonable assumption.

\section{Dynamics of Expenditure Shift}

Because the complexity of the model precludes an analytical exploration of its transitional dynamics, in this section I resort to numerical techniques to examine the short- and long-run effects of a budget-neutral switch in govern- 
ment spending from education to infrastructure, for different values of the parameters characterizing the schooling technology. Intuitive reasoning suggests that such a policy shift would yield ambiguous effects on the economy's growth rate. The more "productive" public capital in infrastructure is in the production of goods (relative to how productive the stock of educated labor is) and the production of educated labor (relative to how productive government spending on education services is), the more likely it is that the growth rate will increase. Put differently, the growth effect should depend positively on the ratio $\alpha / \beta$ and $\kappa_{2} / \kappa_{1}$.

More formally, equation (19) yields

$$
\frac{d \gamma}{d v_{I}}=\gamma\left[\alpha\left(\frac{d \tilde{k}_{G}}{d v_{I}}\right) \tilde{k}_{G}^{-1}+\beta\left(\frac{d \tilde{e}}{d v_{I}}\right) \tilde{e}^{-1}\right]
$$

whereas equation (20), with $d v_{I}=-d v_{E}$ (given that $d \tau=d \varphi=0$ ) yields the following equivalent expression

$$
\frac{d \gamma}{d v_{I}}=\gamma\left[-\frac{\kappa_{1}}{v_{E}}+\frac{\theta_{1}}{\tilde{k}_{G}}\left(\frac{d \tilde{k}_{G}}{d v_{I}}\right)-\frac{\theta_{2}}{\tilde{e}}\left(\frac{d \tilde{e}}{d v_{I}}\right)\right] .
$$

These two results show that the effect on the growth rate is in general ambiguous; as discussed in the Appendix, it depends on the effect of the shock on $d \tilde{k}_{G} / d v_{I}$ and $d \tilde{e} / d v_{I}$, which in turn depends on $\alpha$ and $\beta$, as well $\kappa_{1}$ and $\kappa_{2}$. Everything else equal, the higher the ratio $\kappa_{2} / \kappa_{1}$, the more likely it is that the spending shift will increase growth, as intuition would suggest. In the particular case where $\kappa_{1}=0$ (in which case $\theta_{1}=\theta_{2}=\kappa_{2}$ ), $d \tilde{k}_{G} / d v_{I}>0$, $d \tilde{e} / d v_{I}<0$, and equation (23) shows that $d \gamma / d v_{I}>0$. At the same time, equation (22) shows that this also requires $\alpha / \beta$ to be sufficiently high.

I will focus in what follows on the ratio $\kappa_{2} / \kappa_{1}$ and address the following question: given a range of plausible values for the parameters $\kappa_{1}$ and $\kappa_{2}$, is a budget-neutral reallocation of government expenditure from education services to public investment in infrastructure conducive to higher growth? As 
noted in the introduction, this is an important issue from the practical perspective of a low-income country which must decide on how best to allocate scarce resources to maximize their impact on growth and reduce poverty.

Given that consumption is a forward-looking variable, the numerical solution procedure that I use is the "extended path" method of Fair and Taylor (1984). This procedure is quite convenient (once a discrete-time approximation of the model is written) because it allows one to solve perfect foresight models in their nonlinear form, through an iterative process. ${ }^{10}$ The terminal condition imposed on consumption (the only forward-looking variable here) is that its growth rate at the terminal horizon ( $t+40$ periods here) must be equal to the growth of the private capital stock, given the condition that $c=C / K_{P}$ must be constant along the balanced growth path. I discuss next the calibration procedure and the baseline solution, and then examine the simulation results themselves.

\subsection{Calibration}

The numerical values assigned to the variables and parameters of the system dwell on the existing empirical literature and are given as follows. They are chosen to roughly match some "stylized" facts about low-income developing countries.

I consider an economy with a relatively low stock of public capital to begin with. Specifically, with output $Y$ normalized to 1,000, the initial public capital stock is set at 600 , implying an initial public capital-output ratio of 0.6. This ratio is quite low by industrial-country standards but it is consistent with the average estimate of the net public capital stock obtained by Arestoff

\footnotetext{
${ }^{10}$ See Armstrong, Black, Laxton, and Rose (1998) for an alternative solution technique, based on a Newton "stacked-time" algorithm.
} 
and Hurlin ((2005b, Table 3) for a large group of developing countries. ${ }^{11}$ The private capital stock is set at 1,400, implying that the initial private capitaloutput ratio is 1.4 and the private-public capital ratio is about 2.3. Thus, of the two components of physical capital, public capital is the relatively scarce factor; this is consistent with the view (shared by many observers) that lack of public infrastructure is a major impediment to growth (and private capital accumulation) in poor countries.

The share of educated workers in production (as opposed to teaching in public schools), $\chi$, is set at 95 percent. The elasticities of production of goods with respect to public capital and educated labor, $\alpha$ and $\beta$ respectively, are set equal to 0.15 and 0.45 . The value of $\alpha$ used here corresponds to the one estimated by Easterly and Rebelo (1993) and used by Rioja (2005). By comparison, Baier and Glomm (2001) and Rioja and Glomm (2003) use also an estimate of $\alpha$ of 0.1 , which is close to the figure of 0.11 estimated by Hulten (1996). By comparison, Esfahani and Ramirez (2003, Table 4) found estimates of the elasticities of per capita GDP growth ranging from 0.08 to 0.16 , when infrastructure capital is measured as the number of telephone lines or power generation capacity, whereas Canning (1999) estimates an elasticity of output per worker with respect to infrastructure (as measured by the number of telephone lines) that is on average 0.14 for his full sample, and close to 0.26 for higher-income countries. Similarly, Arestoff and Hurlin ((2005b, Tables 2 and 7$)$ found elasticities of output per worker ranging from 0.05 to 0.19 when infrastructure stocks are used, and from 0.04 to 0.22 when estimates of public capital stocks are used, in the absence of threshold effects.

\footnotetext{
${ }^{11}$ Note, however, that the Arestoff-Hurlin estimates are based on the perpetual inventory method, which consists essentially in cumulating total capital expenditure flows by central governments. These flows include items that are not, strictly speaking, related to infrastructure.
} 
Thus, the estimate used here is consistent with the upper range of the values estimated by Esfahani and Ramirez, and Arestoff and Hurlin, as well as the lower range of Canning's results. The estimates of $\alpha$ and $\beta$ used here imply a share of private capital in output equal to 0.4 . Ortigueira (1998, p. 337) and Rivas (2003, Table 1) also use a share of 0.4, whereas Rioja and Glomm (2003, Table 2) use an estimate of 0.45 .

Consider now the schooling technology. The elasticities with respect to government spending on education services and public capital in infrastructure, $\kappa_{1}$ and $\kappa_{2}$ respectively, are set equal to 0.2 and 0.1 in the base case. The first estimate is twice the size of the estimate used by Rioja (2005) and the econometric estimate obtained by Blankenau et al. (2005) for their full sample. However, it is consistent with the parameter value used by Chen (2005). The higher estimate used here is probably quite appropriate for the group of low-income countries where education (at least at the primary and secondary levels) is to a very large extent publicly provided. ${ }^{12}$ An appropriate value of $\kappa_{2}$ is more difficult to pin down, because of the empirical evidence is microeconomic in nature (see Brenneman and Kerf (2002)). At the same time, as noted earlier, assessing the impact of infrastructure on education and growth is a key purpose of the model. Accordingly, I chose an initial value of $\kappa_{2}=0.1$, and perform sensitivity analysis along the lines discussed below. The initial stock of educated labor, $E$, is calibrated at 2,800; this gives an initial private capital-labor ratio of 0.5 , a public capital-labor ratio of 0.21 , and an overall capital-labor ratio of 71 percent. Keeping in mind that "educated labor" in the present context includes both skilled and unskilled workers employed in

\footnotetext{
${ }^{12}$ Blankenau et al. (2005) found that the elasticity of human capital with respect to government spending on education is close to zero for low-income countries, but this runs counter to intuition. It also does not account for the heterogeneity in public school enrollment discussed in the conclusion.
} 
production, these ratios (together with the capital-output ratios mentioned earlier) capture fairly well the view that the country considered is poor and endowed with a relatively abundant supply of labor, while facing at the same time a relative scarcity of physical (particularly public) capital.

The rate of time preference, $\rho$, is set at 4 percent, a fairly conventional choice in this literature. This leads to a discount factor of approximately 0.96 (see, for instance, Canton (2001, Table 1), and Ghosh and Roy (2004, Tables 1 and 2)). Private consumption, $C$, which is determined from the goods market equilibrium condition (11), represents about 85 percent of output. This value is quite sensible for many low-income countries, where limited resources are allocated to savings and investment. In the model, given the logarithmic specification of instantaneous utility in (2), the intertemporal elasticity of substitution was set implicitly to unity for analytical simplicity. For these numerical exercises, a more general utility function with constant relative risk aversion is used, with an intertemporal elasticity set at 0.2 . This relatively low value is consistent with the evidence showing that the intertemporal elasticity of substitution tends to be low at low levels of income (see Ogaki, Ostry and Reinhart (1996)), a result that may reflect either short planning horizons or liquidity constraints, as discussed by Agénor and Montiel (1999, Chapter 11). ${ }^{13}$

I assume that neither the tax rate nor the spending shares are chosen optimally in the initial equilibrium. This is a reasonable assumption for numerical exercises that are meant to capture the reality of fiscal policymaking in developing (and probably industrial) countries. Specifically, regarding fiscal variables, the tax rate on output (which is also the share of total gov-

\footnotetext{
${ }^{13}$ Of course, using even lower values of the ntertemporal elasticity of substitution would "flatten" the response of consumption to shocks. However, they would not affect the direction of the effect discussed below.
} 
ernment spending in output), $\tau$, is set at 0.2 . This value is in line with actual ratios for many low-income countries, where taxation (which is essentially indirect in nature) provides a more limited source of revenue than in higher-income countries. The initial shares of government spending on infrastructure services and education services, $v_{I}$ and $v_{E}$ respectively, are set at 0.3 and 0.2 . The coefficient $\varphi$ is thus 0.5 , as implied by the budget constraint (13). This is quite reasonable, given that $\varphi$ represents in practice the share of not only government wages in total tax revenue but also other current spending (including transfers to households and subsidies), which were not explicitly accounted for in the model. Multiplying these shares by the tax rate implies therefore that spending on infrastructure investment represents 6.0 percent of output in the base period, whereas spending on education services amounts to 4.0 percent of output. By comparison, Rioja (2005, p. 6) reports averages for $v_{I}$ and $v_{E}$ of 7.3 percent and 2.9 percent of GDP, respectively, for a group of 9 upper-income Latin American countries, whereas Rioja and Glomm (2003, Table 1) report shares of 3.05 and 3.13 percent for a larger group of 17 Latin American countries. However, these studies also indicate that there is considerable heterogeneity across countries. This is also what one would expect for low-income countries, based on the data on capital expenditure compiled by Arestoff and Hurlin (2005a). The estimates used here can be viewed as representing the "intermediate" case of a government committed to allocating half of its resources to physical and human capital accumulation.

Calibration of the model around these initial values and parameters (which involves also determining appropriate multiplicative constants in the production functions for goods and educated labor) produces the baserun solution. Given the values described above, initial ratios of $c, e$, and $k_{G}$ are, respec- 
tively, $0.61,2.00$, and 0.43 , whereas the initial steady-state growth rate is equal to 3.4 percent. ${ }^{14}$ In the results reported below, three alternative values are chosen for the parameters characterizing the schooling technology, $\kappa_{1}$ and $\kappa_{2}$ : the base case referred to earlier, with $\kappa_{1}=0.2$ and $\kappa_{2}=0.1$, as well as two alternative scenarios: a "high infrastructure" case, where $\kappa_{1}=0.2$ and $\kappa_{2}=0.2$, and a "high education services" case, where $\kappa_{1}=0.3$ and $\kappa_{2}=0.1$. A new baseline is, of course, calculated for each set of parameters.

\subsection{Policy Experiment}

Consider a budget-neutral shift in the composition of government spending that takes the form of an increase in the share of investment in infrastructure, from 0.3 to 0.4 , coupled with a reduction in the share of spending on education services, from 0.2 to 0.1 . In proportion of output, this shift represents an increase in spending on infrastructure investment from 6 to 8 percent, with a concomitant reduction in spending on education from 4 to 2 percent. The same experiment is run for the three cases described earlier regarding the values of the parameters characterizing the schooling technology. By contrasting these three cases, the simulations provide a sense of the importance of the inclusion of infrastructure capital in the education technology for the transitional dynamics and the steady-state results.

The effect of the expenditure switch on the consumption-private capital ratio, the ratio of educated labor to private capital, and the ratio of public to private capital are shown in Figure 1. The three lines correspond to the three sets of values for $\kappa_{1}$ and $\kappa_{2}$ given earlier, with the continuous plot corresponding to the "base" case of $\kappa_{1}=0.2$ and $\kappa_{2}=0.1$.

\footnotetext{
${ }^{14}$ To calculate the steady-state growth rate, I use the appropriate discrete time formulation corresponding to (4) with an elasticity of substitution $\sigma$ different from unity, that is, $\left\{\left[1+s\left(Y / K_{P}\right)\right] /(1+\rho)\right\}^{\sigma}-1$.
} 
On impact, neither stock of capital (public or private) changes, and the stock of educated labor does not change either. As a result, output and tax revenues are also constant. But in all three cases, consumption (and thus the ratio of consumption to private capital) jumps upward. In subsequent periods, the shift in government spending translates into a lower stock of educated labor, whereas the stock of public capital in infrastructure increases. The latter effect raises the marginal productivity of private capital, whereas the former reduces it. Although the elasticity of output with respect to public infrastructure is substantially lower than its elasticity with respect to labor, the net effect is an increase in the marginal productivity of capital, thereby raising the incentive to save and invest. The intertemporal substitution effects tends therefore to reduce consumption on impact. At the same time, however, the positive income effect (associated with the higher capital stock and output) tends to increase consumption. Given the relatively small value of the elasticity of substitution, the latter effect dominates and consumption increases, as noted earlier.

The combination of increasing stocks of private and public capital translates also, during a first phase, into higher output, despite a falling stock of educated labor. The adjustment process, for all three sets of values for $\left(\kappa_{1}, \kappa_{2}\right)$, is non-monotonic: at first, the consumption-private capital ratio and the ratio of public to private capital increase, whereas the ratio of educated labor to private capital falls. As could be expected, the drop in the stock of educated labor is lower in the "high infrastructure" case (where $\kappa_{1}=0.2$ and $\left.\kappa_{2}=0.2\right)$, whereas it is more pronounced in the "high education services" case (where $\kappa_{1}=0.3$ and $\kappa_{2}=0.1$ ). The initial increase in the consumptionprivate capital ratio is also considerably more pronounced in the "high education services" case. The reason is that the future increase in the marginal 
product of capital is less pronounced in that case; the incentive to shift consumption forward (and save more today) is therefore mitigated and the income effect largely dominates. After reaching a peak, the consumptionprivate capital and public-private capital ratios start falling, whereas the educated labor-private capital ratio starts increasing. Essentially, because of an initial phase of higher private capital accumulation, and lower accumulation of educated labor, the marginal product of capital begins to fall - and so do output and consumption. In fact, in the "base" and "high infrastructure" scenarios, adjustment of the consumption-private capital ratio is oscillatory: after the third period, the ratio drops below its baseline value and recovers only gradually. This drop is more pronounced in the "high infrastructure" case, because the adverse effect of the spending shift on the rate of accumulation of educated labor is less pronounced, implying that the marginal product of capital falls by less, and therefore that private capital accumulation is higher. In the long run, the shock has no discernible effect on the consumption-capital ratio in the "base" and "high infrastructure" cases, and only a small positive effect in the "high education services" case. By contrast, the educated labor-private capital ratio converges to a permanently lower value relative to the baseline scenario (by about -0.6 percentage points in the "base" and "high infrastructure" cases, and -1.1 percentage points in the "high education services" case), whereas the public-private capital ratio converges to a permanently higher value (about 2.4 percentage points in all three cases). For the public-private capital ratio, the long-run change is not significantly affected by the choice of the parameters $\left(\kappa_{1}, \kappa_{2}\right)$, in contrast to the other ratios. But in all three scenarios, the effect on the economy's growth rate, is negligible in the long run, with a slightly higher effect in the "high infrastructure" case relative to the other two cases. 
The foregoing discussion suggests therefore that, given the calibration adopted, a budget-neutral shift in spending from education to infrastructure has limited effects on long-run growth. In a sense, increasing spending on one component while decreasing the other simultaneously tends to have largely offsetting effects, given the structure of parameters and the overall calibration. At the same time, however, simulation results do support the intuition that long-run effects on growth of a reallocation of spending toward infrastructure investment are higher when infrastructure has a larger impact on the schooling technology. This implies that relatively large shifts in spending would be required for growth to fall. This is in contrast with the results of Rioja (2005), who showed - using an OLG model and a schooling technology that does not depend on infrastructure - that a relatively small shift in spending of the type considered here unambiguously lowers steady-state growth. ${ }^{15}$

\section{Growth-Maximizing Policies}

The numerical simulations reported in the previous section illustrate well the potential trade-off between spending on infrastructure investment and spending on education services. This trade-off has also been well recognized in the recent literature on "flow" models of government expenditure, in which infrastructure services affect the economy's ability to produce human capital (see Agénor (2005b)). This section discusses how the presence of the stock of public infrastructure capital in the schooling technology affects the determination of growth-maximizing fiscal policies.

\footnotetext{
${ }^{15}$ In the present context, Rioja's results correspond to the case where $\kappa_{2}=0$. In that particular case, numerical simulations also indicate that the expenditure shift considered here would lower the steady-state growth rate if $\kappa_{1}$ is relatively large with respect to $\alpha$.
} 
I first examine the determination of the optimal tax rate, holding all expenditure shares (that is, the composition of tax revenues) constant. Let $\varepsilon_{\tilde{y} / z}$ denote the elasticity of the steady-state value of $y$ with respect to $z$; setting $\partial \gamma / \partial \tau=0$ in equations (19), (20) and (21) yields the following system of equations in $\tau, \varepsilon_{\tilde{k}_{G} / \tau}$, and $\varepsilon_{\tilde{e} / \tau}$ :

$$
\begin{gathered}
\tau^{*} /\left(1-\tau^{*}\right)=\alpha \varepsilon_{\tilde{k}_{G} / \tau}+\beta \varepsilon_{\tilde{e} / \tau} \\
\theta_{1} \varepsilon_{\tilde{k}_{G} / \tau}-\theta_{2} \varepsilon_{\tilde{e} / \tau}=-\kappa_{1}, \\
(1-\alpha) \varepsilon_{\tilde{k}_{G} / \tau}-\beta \varepsilon_{\tilde{e} / \tau}=1 .
\end{gathered}
$$

The last two equations can be solved simultaneously for $\varepsilon_{\tilde{k}_{G} / \tau}$ and $\varepsilon_{\tilde{e} / \tau}$, yielding:

$$
\varepsilon_{\tilde{k}_{G} / \tau}=\left(\beta \kappa_{1}+\theta_{2}\right) / \Delta, \quad \varepsilon_{\tilde{e} / \tau}=\left[\theta_{1}+(1-\alpha) \kappa_{1}\right] / \Delta,
$$

where $\Delta=-\beta \theta_{1}+(1-\alpha) \theta_{2}=(1-\alpha-\beta)\left(\kappa_{1}+\kappa_{2}\right)>0$.

Simplifying these expressions yields

$$
\varepsilon_{\tilde{k}_{G} / \tau}=\varepsilon_{\tilde{e} / \tau}=\frac{1}{1-\alpha-\beta}
$$

which indicates that the elasticities of the steady-state values of the publicprivate capital ratio and the educated labor-capital ratio with respect to the tax rate must be the same at the optimum. These results can be substituted in equation (24) to lead to the following proposition:

Proposition 1. With spending shares on education services and infrastructure investment held constant, the growth-maximizing value of the tax rate is $\tau^{*}=\alpha+\beta \in(0,1)$.

This result is similar to the one derived in a previous contribution (see Agénor $(2005 a))$, in which public infrastructure was treated as a flow. In a 
sense, therefore, these results confirm those obtained in Barro-type models where human capital (embodied or disembodied) is absent. In the present setting, where educated labor is also productive, the optimal tax rate is higher than $\alpha$ by a factor $\beta .^{16}$

I now examine the optimal allocation of spending between education services, $v_{E}$, and infrastructure investment, $v_{I}$, for a given tax rate, $\tau$. As a result of the budget constraint (13), and with $\varphi$ constant, only one of these shares can be chosen independently. Setting $\partial \gamma / \partial v_{I}=0$ in equations (19), (20) and (21), and using (13), yields the following system of equations in $\tau$, $\varepsilon_{\tilde{k}_{G} / v_{I}}$, and $\varepsilon_{\tilde{e} / v_{I}}$ :

$$
\begin{gathered}
\alpha \varepsilon_{\tilde{k}_{G} / v_{I}}+\beta \varepsilon_{\tilde{e} / v_{I}}=0, \\
\theta_{1} \varepsilon_{\tilde{k}_{G} / v_{I}}-\theta_{2} \varepsilon_{\tilde{e} / v_{I}}=\kappa_{1}\left[v_{I}^{*} /\left(1-v_{I}^{*}-\varphi\right)\right], \\
(1-\alpha) \varepsilon_{\tilde{k}_{G} / v_{I}}-\beta \varepsilon_{\tilde{e} / v_{I}}=1,
\end{gathered}
$$

where $\theta_{1}$ and $\theta_{2}$ are as defined before. Combining (27) and (29) yields

$$
\varepsilon_{\tilde{k}_{G} / v_{I}}=1
$$

which indicates that the elasticity of the steady-state value of the publicprivate capital ratio with respect to the share of spending on infrastructure must be equal to unity at the optimum. From (27), this implies that $\varepsilon_{\tilde{e} / v_{I}}=$ $-\alpha / \beta$. Substituting both results in (28) yields, with $\varphi=0$ for simplicity,

$$
\frac{v_{I}^{*}}{1-v_{I}^{*}}=\kappa_{1}^{-1}\left(\theta_{1}+\frac{\alpha \theta_{2}}{\beta}\right) \text {. }
$$

Further manipulations lead to the following proposition:

\footnotetext{
${ }^{16}$ Note that the optimal tax rate is considerably higher than the value used in the numerical simulations presented in the previous section (0.6, compared to 0.2). However, it should be kept in mind that the present analysis abstracts from collection costs, which are sizable in low-income countries. These costs may explain why, in practice, tax rates tend to be much lower than what would be otherwise optimal from a growth perspective.
} 
Proposition 2. With a constant tax rate, the growth-maximizing allocation of spending between education services and infrastructure investment is given by

$$
v_{I}^{*}=\frac{\alpha \kappa_{1}+(\alpha+\beta) \kappa_{2}}{(\alpha+\beta)\left(\kappa_{1}+\kappa_{2}\right)} \in(0,1), \quad v_{E}^{*}=1-v_{I}^{*}
$$

Thus, in general, the growth-maximizing share of investment in infrastructure depends not only on the parameters characterizing the production technology but also on those characterizing the schooling technology, $\kappa_{1}$ and $\kappa_{2}$. In particular, the following corollary can be established from Proposition 2 :

Corollary 1. An increase in the elasticity $\kappa_{1}\left(\kappa_{2}\right)$ in the schooling technology lowers (increases) the growth-maximizing share of spending on infrastructure investment.

It can also be verified that, when $\kappa_{2}=0, v_{I}^{*}=\alpha /(\alpha+\beta)$, as I have shown elsewhere (see Agénor (2005a)). Put differently, if infrastructure capital has no effect on the schooling technology, the optimal allocation of public expenditure depends solely on the relative importance of elasticities of production with respect to labor and public capital. And naturally enough, if government spending on education services has no effect on the production of educated labor ( so that $\kappa_{1}=0$ ), then $v_{I}^{*}=1$. The same result is obtained if educated labor has no effect on production $(\beta=0)$, regardless of the values of $\kappa_{1}$ and $\kappa_{2}$.

Moreover, the formula for $v_{I}^{*}$ provided in (30) is exactly identical to the optimal rule derived by Agénor (2005b) in a model in which it is the flow of infrastructure spending that affects the schooling technology, and constant returns to scale hold only with respect to the number of teachers, expen- 
diture on infrastructure, and the stock of raw labor. ${ }^{17}$ Put differently, the optimal allocation described in (30) does not depend on whether the impact of infrastructure on the education technology is measured as a flow or a stock effect.

Finally, the following result can also be readily established from (30):

Corollary 2. The growth-maximizing share of investment on infrastructure is such that $v_{I}^{*}>\alpha$, regardless of whether $\kappa_{2} \geq 0$.

In other words, the optimal spending share on infrastructure investment exceeds the elasticity of output with respect to public capital in infrastructure, as predicted by the Barro rule. This result holds even if $\kappa_{2}=0$; the reason of course is that a higher stock of public capital in infrastructure raises not only the marginal productivity of private capital but also the marginal productivity of educated labor.

\section{Concluding Remarks}

The purpose of this paper has been to analyze trade-offs between public spending on infrastructure investment and the provision of education services in an endogenous growth model where (unlike Lucas-type models) knowledge is embodied in workers. Schooling is in principle compulsory, but excess demand for the acquisition of skills leads the government to ration access to schools, to avoid overcrowding. Public infrastructure in the model is treated as a stock, and the economy's technology is such that only educated workers can be used for training or to produce of goods. A crucial feature of the model is that the production of educated labor requires not only government

\footnotetext{
${ }^{17}$ In that paper, I also assumed that spending on education services (measured as a proportion of the number of teachers) affects the overall quality of schooling, and thus the productivity of all inputs.
} 
spending on education services but infrastructure capital as well. The key idea is that go to school, you need roads; to read and study (at night), or to connect a computer, you need electricity; to get girls to attend school, adequate water and sanitation facilities must be provided. A number of recent microeconomic studies have indeed provided evidence that infrastructure has a significant impact on the education process.

After deriving the balanced growth path of the model, numerical techniques were used to examine the transitional and long-run effects of a budgetneutral switch in government spending from education to infrastructure, for different values of the parameters characterizing the schooling technology. It was shown that reallocating funds from education to infrastructure increases the growth rate (even though the stock of educated labor grows at a slower rate), even if public infrastructure capital has only a moderate effect on the production of educated labor.

The optimal (growth-maximizing) tax rate and shares of government spending on infrastructure investment and education services were then determined. The optimal tax rate was shown to be equal to the sum of the elasticities of output with respect to public infrastructure and educated labor, in line with results obtained elsewhere with flow models. It was also shown that the optimal allocation of public spending depends not only on the elasticity of output with respect to infrastructure capital and educated labor (as would be expected), but also on the parameters characterizing the production technology. In particular, the optimal spending share on infrastructure investment exceeds the elasticity of output with respect to public capital in infrastructure, as predicted by the Barro rule. Moreover, the lower the ratio of elasticities of the schooling technology with respect to educated labor and infrastructure capital, the lower the share of spending on infrastructure in- 
vestment. Finally, it was also shown that the optimal allocation rule does not depend on whether the impact of infrastructure on the schooling technology is measured as a flow or a stock effect. Because, models in which infrastructure spending is modeled as a flow are much more tractable analytically, this result carries some importance for future work in this area.

The analysis can be extended in several directions. One possibility would be to account for public capital in education, which would require treating schools, libraries, and so on, as a stock. Another direction would be to consider a mixed (private-public) education system (as, for instance, in Chen (2005)). According to Chen (2005, Table 2), private school enrollment as a proportion of total enrollment in secondary schools varies significantly even among low-income countries (for which the model developed here is perhaps more appropriate). For instance, it ranges from about 9 percent in Mali to 48 percent in Burkina Faso and 84 percent in Haiti. This extension would allow a discussion of the potential trade-offs between subsidies to private schools and direct government involvement in education. A third extension would be to introduce congestion costs, not only in infrastructure (as is done in many contributions to the literature on growth and public investment, such as Turnovsky (1997), Piras (2001), and Gómez (2004)) but also congestion costs in education (as discussed in Agénor (2005a, 2005b)). As noted in various studies, students-to-teachers ratios tend to be very high in low-income countries compared to industrial countries, thereby hampering the ability to acquire knowledge. The resulting model would then allow a discussion of the implications of various forms of congestion for the determination of growth-maximizing policies. Finally, a fourth extension would be to introduce health considerations. Recent evidence for developing countries suggests that infrastructure may affect not only the creation and transmission 
of knowledge (as in the present study), but also the efficiency of governmentprovided health services. The evidence also suggests that health services enhance not only the productivity of workers, but also household utilityhealthier individuals may enjoy consumption more - and the ability to learn and study. Agénor and Neanidis (2006) examine how these interactions affect the optimal allocation of government spending between infrastructure, education and health services. 


\section{Appendix}

The steady-growth equilibrium is determined as follows. First, the household budget constraint (equation (3)) can be rewritten as, using (1),

$$
\dot{K}_{P}=(1-\tau) \chi^{\beta}\left(\frac{K_{G}}{K_{P}}\right)^{\alpha}\left(\frac{E}{K_{P}}\right)^{\beta} K_{P}-C+(1-\chi) w_{G} E,
$$

that is, given that $(1-\chi) w_{G} E=\varphi \tau Y$,

$$
\frac{\dot{K}_{P}}{K_{P}}=[1-\tau(1-\varphi)] \chi^{\beta} k_{G}^{\alpha} e^{\beta}-c,
$$

where $c=C / K_{P}, k_{G}=K_{G} / K_{P}$, and $e=E / K_{P}$.

Similarly, equation (4) can be rewritten as

$$
\frac{\dot{C}}{C}=s \chi^{\beta} k_{G}^{\alpha} e^{\beta}-\rho
$$

Equation (9) gives

$$
\frac{\dot{E}}{E}=A_{E}\left(\frac{G_{E}}{E}\right)^{\kappa_{1}}\left[\left(\frac{K_{G}}{K_{P}}\right)\left(\frac{K_{P}}{E}\right)\right]^{\kappa_{2}}=A_{E}\left(\frac{G_{E}}{E}\right)^{\kappa_{1}}\left(\frac{k_{G}}{e}\right)^{\kappa_{2}},
$$

so that, noting that $G_{E} / E=\tau\left(G_{E} / \tau Y\right)(Y / E)$, and using (12),

$$
\frac{\dot{E}}{E}=A_{E}\left(\tau v_{E}\right)^{\kappa_{1}}\left[\left(\frac{Y}{K_{P}}\right)\left(\frac{K_{P}}{E}\right)\right]^{\kappa_{1}}\left(\frac{k_{G}}{e}\right)^{\kappa_{2}} .
$$

Using (1), which implies that $Y / K_{P}=\chi^{\beta} k_{G}^{\alpha} e^{\beta}$, yields

$$
\frac{\dot{E}}{E}=A_{E} \chi^{\beta \kappa_{1}}\left(\tau v_{E}\right)^{\kappa_{1}} k_{G}^{\theta_{1}} e^{-\theta_{2}},
$$

where, as noted in the text, $\theta_{1} \equiv \alpha \kappa_{1}+\kappa_{2}$ and $\theta_{2} \equiv(1-\beta) \kappa_{1}+\kappa_{2}$.

From (14), using (1) and (12), and noting that $Y / K_{G}=\left(Y / K_{P}\right) k_{G}^{-1}$,

$$
\frac{\dot{K}_{G}}{K_{G}}=\frac{v_{I} \tau Y}{K_{G}}=\tau v_{I} \chi^{\beta} k_{G}^{\alpha-1} e^{\beta} .
$$

Combining equations (A1), (A2), (A4), and (A5) yields

$$
\frac{\dot{c}}{c}=\Omega \chi^{\beta} k_{G}^{\alpha} e^{\beta}+c-\rho,
$$




$$
\begin{gathered}
\frac{\dot{e}}{e}=A_{E} \chi^{\beta \kappa_{1}}\left(\tau v_{E}\right)^{\kappa_{1}} k_{G}^{\theta_{1}} e^{-\theta_{2}}-\mu \chi^{\beta} k_{G}^{\alpha} e^{\beta}+c, \\
\frac{\dot{k}_{G}}{k_{G}}=\left(\frac{\tau v_{I}}{k_{G}}-\mu\right) \chi^{\beta} k_{G}^{\alpha} e^{\beta}+c,
\end{gathered}
$$

where $\Omega \equiv s-\mu$ and $\mu \equiv 1-\tau(1-\varphi) \in(0,1)$. Given that $s \equiv(1-\tau)(1-\alpha-\beta)$, then $\Omega \equiv-(1-\tau)(\alpha+\beta)-\tau \varphi<0$.

To investigate the dynamics in the vicinity of the steady state, these equations can be linearized to give

$$
\left[\begin{array}{c}
\dot{c} \\
\dot{e} \\
\dot{k}_{G}
\end{array}\right]=\left[\begin{array}{ccc}
\tilde{c} & a_{12} & a_{13} \\
\tilde{e} & a_{22} & a_{23} \\
\tilde{k}_{G} & a_{32} & a_{33}
\end{array}\right]\left[\begin{array}{c}
c-\tilde{c} \\
e-\tilde{e} \\
k_{G}-\tilde{k}_{G}
\end{array}\right],
$$

where $\tilde{x}$ denotes the stationary value of $x$ and the $a_{i j}$ are given by

$$
\begin{gathered}
a_{12}=\beta \tilde{c} \Omega \chi^{\beta} \tilde{k}_{G}^{\alpha} \tilde{e}^{\beta-1}<0, \\
a_{13}=\alpha \tilde{c} \Omega \chi^{\beta} \tilde{k}_{G}^{\alpha-1} \tilde{e}^{\beta}<0, \\
a_{22}=-\theta_{2} A_{E} \chi^{\beta \kappa_{1}}\left(\tau v_{E}\right)^{\kappa_{1}} \tilde{k}_{G}^{\theta_{1}} \tilde{e}^{-\theta_{2}}-\beta \mu \chi^{\beta} \tilde{k}_{G}^{\alpha} \tilde{e}^{\beta}<0, \\
a_{23}=\theta_{1} A_{E} \chi^{\beta \kappa_{1}}\left(\tau v_{E}\right)^{\kappa_{1}} \tilde{k}_{G}^{\theta_{1}-1} \tilde{e}^{1-\theta_{2}}-\alpha \mu \chi^{\beta} \tilde{k}_{G}^{\alpha-1} \tilde{e}^{1+\beta}, \\
a_{32}=\beta \tilde{k}_{G}\left(\tau v_{I} \tilde{k}_{G}^{-1}-\mu\right) \chi^{\beta} \tilde{k}_{G}^{\alpha} \tilde{e}^{\beta-1}, \\
a_{33}=\alpha\left(\tau v_{I} \tilde{k}_{G}^{-1}-\mu\right) \chi^{\beta} \tilde{k}_{G}^{\alpha} \tilde{e}^{\beta}-\tau v_{I} \chi^{\beta} \tilde{k}_{G}^{\alpha-1} \tilde{e}^{\beta} .
\end{gathered}
$$

To establish the sign of $a_{23}, a_{32}$ and $a_{33}$, note that from the alternative definitions of the steady-state growth rate $\gamma$ given in the text, as well as the fact that, from (A1), $\gamma=\mu \chi^{\beta} \tilde{k}_{G}^{\alpha} \tilde{e}^{\beta}-\tilde{c}$, we have

$$
\begin{gathered}
a_{23}=\theta_{1} \tilde{e} \gamma / \tilde{k}_{G}-\alpha \tilde{e}(\gamma+\tilde{c}) / \tilde{k}_{G}, \\
a_{32}=\beta \tilde{k}_{G} \gamma / \tilde{e}-\beta \tilde{k}_{G}(\gamma+\tilde{c}) / \tilde{e}=-\beta \tilde{k}_{G} \tilde{c} / \tilde{e}<0, \\
a_{33}=\alpha[\gamma-(\gamma+\tilde{c})]-\gamma=-\alpha \tilde{c}-\gamma<0 .
\end{gathered}
$$

The sign of $a_{23}$ remains in general ambiguous. A sufficient (although not necessary) for $a_{23}<0$ is $\theta_{1}<\alpha$. Given that $\theta_{1} \equiv \alpha \kappa_{1}+\kappa_{2}$, this condition is equivalent to $\alpha\left(1-\kappa_{1}\right)>\kappa_{2}$.

Among the three variables whose dynamics drive the system, $c$ can jump whereas $e$ and $k_{G}$ are predetermined. Saddlepath stability requires therefore one unstable (positive) root. The Routh-Hurwicz conditions imply that the 
determinant of the Jacobian matrix of partial derivatives of the dynamic system (A9), J, must be positive (in order to exclude one or three negative roots), whereas its trace must be negative (in order to guarantee at least one negative root):

$$
\operatorname{tr} \mathbf{J}=\tilde{c}+a_{22}+a_{33}<0,
$$

$$
\operatorname{det} \mathbf{J}=\tilde{c}\left(a_{22} a_{33}-a_{23} a_{32}\right)-\tilde{e}\left(a_{12} a_{33}-a_{13} a_{32}\right)+\tilde{k}_{G}\left(a_{12} a_{23}-a_{13} a_{22}\right)>0 .
$$

From the definition of $a_{22}$, it can be established that $a_{22}=-\theta_{2} \gamma-\beta(\gamma+\tilde{c})$. Combining this result with the above definition of $a_{33}$ yields

$$
\operatorname{tr} \mathbf{J}=(1-\alpha-\beta) \tilde{c}-\left(1+\beta+\theta_{2}\right) \gamma,
$$

that is, given that $\theta_{2} \equiv(1-\beta) \kappa_{1}+\kappa_{2}$,

$$
\operatorname{tr} \mathbf{J}=(1-\alpha-\beta) \tilde{c}-\left[1+\left(1-\kappa_{1}\right) \beta+\kappa_{1}+\kappa_{2}\right] \gamma .
$$

The expression tr $\mathbf{J}$ is therefore ambiguous in sign in general. The expression for $\operatorname{det} \mathbf{J}$ is also quite complex; simple inspection of the signs in (A11) indicates that the condition $\operatorname{det} \mathbf{J}>0$ does not necessarily hold. By implication, saddlepath stability in the neighborhood of the balanced-growth path cannot be guaranteed analytically. Nevertheless, the numerical simulations discussed in the text show that the system is indeed saddlepath stable for the parameter values chosen.

Setting $\dot{c}=\dot{e}=\dot{k}_{G}=0$ in equations (A6), (A7), and (A8) yields

$$
\begin{gathered}
\tilde{c}=\rho-\Omega \tilde{k}_{G}^{\alpha} \tilde{e}^{\beta}, \\
A_{E} \chi^{\beta \kappa_{1}}\left(\tau v_{E}\right)^{\kappa_{1}} \tilde{k}_{G}^{\theta_{1}} \tilde{e}^{-\theta_{2}}-\mu \chi^{\beta} \tilde{k}_{G}^{\alpha} \tilde{e}^{\beta}+\tilde{c}=0, \\
\left(\tau v_{I} \tilde{k}_{G}^{-1}-\mu\right) \chi^{\beta} \tilde{k}_{G}^{\alpha} \tilde{e}^{\beta}+\tilde{c}=0 .
\end{gathered}
$$

Given that $\Omega<0$, the steady-state value of the consumption-private capital ratio is positive $(\tilde{c}>0)$. Substituting (A12) in (A13) and (A14) yields the following system in $\tilde{e}$ and $\tilde{k}_{G}$ :

$$
\begin{gathered}
Q_{1}\left(\tilde{e}, \tilde{k}_{G}\right)=A_{E} \chi^{\beta \kappa_{1}}\left(\tau v_{E}\right)^{\kappa_{1}} \tilde{k}_{G}^{\theta_{1}} \tilde{e}^{-\theta_{2}}-s \chi^{\beta} \tilde{k}_{G}^{\alpha} \tilde{e}^{\beta}+\rho=0, \\
Q_{2}\left(\tilde{e}, \tilde{k}_{G}\right)=\left(\tau v_{I} \tilde{k}_{G}^{-1}-s\right) \chi^{\beta} \tilde{k}_{G}^{\alpha} \tilde{e}^{\beta}+\rho=0,
\end{gathered}
$$

which can be linearized in the vicinity of the balanced-growth equilibrium to solve for $\tilde{e}$ and $\tilde{k}_{G}$. 
To determine the steady-state impact of a budget-neutral increase in $v_{I}$ (that is, with $d v_{I}=-d v_{E}$ ), these two equations can be manipulated to yield

$$
\left[\begin{array}{ll}
b_{11} & b_{12} \\
b_{21} & b_{22}
\end{array}\right]\left[\begin{array}{c}
d \tilde{e} \\
d \tilde{k}_{G}
\end{array}\right]=\left[\begin{array}{l}
b_{13} \\
b_{23}
\end{array}\right] d v_{I}
$$

where

$$
\begin{gathered}
b_{11}=-\theta_{2} A_{E} \chi^{\beta \kappa_{1}}\left(\tau v_{E}\right)^{\kappa_{1}} \tilde{k}_{G}^{\theta_{1}} \tilde{e}^{-\theta_{2}-1}-\beta s \chi^{\beta} \tilde{k}_{G}^{\alpha} \tilde{e}^{\beta-1}<0, \\
b_{12}=\theta_{1} A_{E} \chi^{\beta \kappa_{1}}\left(\tau v_{E}\right)^{\kappa_{1}} \tilde{k}_{G}^{\theta_{1}-1} \tilde{e}^{-\theta_{2}}-\alpha s \chi^{\beta} \tilde{k}_{G}^{\alpha-1} \tilde{e}^{\beta}, \\
b_{13}=-\kappa_{1} A_{E} \chi^{\beta \kappa_{1}} \tau^{\kappa_{1}} v_{E}^{\kappa_{1}-1} \tilde{k}_{G}^{\theta_{1}} \tilde{e}^{-\theta_{2}}<0, \\
b_{21}=\beta\left(\tau v_{I} \tilde{k}_{G}^{-1}-s\right) \chi^{\beta} \tilde{k}_{G}^{\alpha} \tilde{e}^{\beta-1}, \\
b_{22}=\alpha\left(\tau v_{I} \tilde{k}_{G}^{-1}-s\right) \chi^{\beta} \tilde{k}_{G}^{\alpha-1} \tilde{e}^{\beta}-\tau v_{I} \chi^{\beta} \tilde{k}_{G}^{\alpha-2} \tilde{e}^{\beta}, \\
b_{23}=\tau \chi^{\beta} \tilde{k}_{G}^{\alpha-1} \tilde{e}^{\beta}>0 .
\end{gathered}
$$

To establish the sign of $b_{12}$, note that, using (A15),

$$
b_{12}=\left(\theta_{1}-\alpha\right) s \chi^{\beta} \tilde{k}_{G}^{\alpha-1} \tilde{e}^{\beta}-\theta_{1} \rho / \tilde{k}_{G},
$$

which, given the condition $\theta_{1}<\alpha$ imposed earlier (to ensure that $a_{23}<0$ ), $b_{12}<0$.

Similarly, to establish the signs of $b_{21}$ and $b_{22}$, note that, using (A16), ${ }^{18}$

$$
\begin{gathered}
b_{21}=-\beta \rho / \tilde{e}<0, \\
b_{22}=-\alpha \rho / \tilde{k}_{G}-\tau v_{I} \chi^{\beta} \tilde{k}_{G}^{\alpha-2} \tilde{e}^{\beta}<0 .
\end{gathered}
$$

Solving equations (A17) yields

$$
\frac{d \tilde{e}}{d v_{I}}=\frac{b_{13} b_{22}-b_{12} b_{23}}{b_{11} b_{22}-b_{12} b_{21}}, \quad \frac{d \tilde{k}_{G}}{d v_{I}}=\frac{b_{11} b_{23}-b_{21} b_{13}}{b_{11} b_{22}-b_{12} b_{21}} .
$$

These expressions are in general ambiguous in sign. It can be established, however, that the lower the ratio $\kappa_{1} / \kappa_{2}$, the larger will be the drop in $\tilde{e}$ and the higher will be the increase in $\tilde{k}_{G}$, and the more likely it is that the consumption-private capital ratio will increase (as implied by (A12)) and the steady-state growth rate $\gamma$ to rise.

\footnotetext{
${ }^{18}$ Alternatively, $b_{22}$ can be written as $b_{22}=-(1-\alpha) \tau v_{I} \chi^{\beta} \tilde{k}_{G}^{\alpha-2} \tilde{e}^{\beta}-\alpha s \chi^{\beta} \tilde{k}_{G}^{\alpha-1} \tilde{e}^{\beta}<0$.
} 


\section{References}

Agénor, Pierre-Richard, "Infrastructure, Public Education and Growth with Congestion Costs," Working Paper No. 47, Centre for Growth and Business Cycle Research, University of Manchester (January 2005a). Forthcoming, European Journal of Political Economy.

—_ "Fiscal Policy and Endogenous Growth with Public Infrastructure," Working Paper No. 59, Centre for Growth and Business Cycle Research, University of Manchester (September 2005b).

—_, "Infrastructure Investment and Maintenance Expenditure: Optimal Allocation Rules in a Growing Economy," Working Paper No. 60, Centre for Growth and Business Cycle Research, University of Manchester (September 2005c).

Agénor, Pierre-Richard, and Kyriakos Neanidis, "Health, Public Infrastructure and Education in a Growing Economy," unpublished, University of Manchester (January 2006).

Arestoff, Florence, and Christophe Hurlin, "The Productivity of Public Capital in Developing Countries," unpublished, University of Orléans (March 2005a).

Arestoff, Florence, and Christophe Hurlin, "Threshold Effects in the Productivity of Public Capital in Developing Countries," unpublished, University of Orléans (May 2005b).

Armstrong, J., R. Black, Douglas Laxton, and D. Rose, "A Robust Method for Simulating Forward-Looking Models," Journal of Economic Dynamics and Control, 22 (April 1998), 489-501.

Baier, Scott L., and Gerhard Glomm, "Long-run Growth and Welfare Effects of Public Policies with Distortionary Taxation," Journal of Economic Dynamics and Control, 25 (December 2001), 1007-42.

Barro, Robert J., "Government Spending in a Simple Model of Endogenous Growth," Journal of Political Economy, 98 (October 1990), s103-s25.

Blankenau, William F., Nicole B. Simpson, and Marc Tomljanovich, "Public Education Expenditures, Taxation and Growth: Linking Data to Theory," unpublished, Kansas State University (April 2005).

Brenneman, Adam, and Michel Kerf, "Infrastructure and Poverty Linkages: A Literature Review," unpublished, the World Bank (December 2002).

Canton, Erik, "Fiscal Policy in a Stochastic Model of Endogenous Growth," Economic Modelling, 18 (January 2001), 19-47.

Chen, Hung-ju, "Educational Systems, Growth and Income Distribution: A Quantitative Analysis," Journal of Development Economics, 76 (April 2005), 
$325-53$.

Eicher, Theo, and Stephen J. Turnovsky, "Non-Scale Models of Endogenous Growth," Economic Journal, 109 (July 1999), 394-415.

—_ "Scale, Congestion, and Growth," Economica, 67 (August 2000), 325-46.

Esfahani, Hadi S., and Maria T. Ramírez, "Institutions, Infrastructure, and Economic Growth," Journal of Development Economics , 70 (April 2003), 443-77.

Fair, Ray C., and John B. Taylor, "Solution and Maximum Likelihood Estimation of Dynamic Nonlinear Rational Expectations Models," Econometrica, 51 (July 1983), 1169-96.

Fisher, Walter H., and Stephen Turnovsky, "Public Investment, Congestion, and Private Capital Accumulation," Economic Journal, 108 (March 1998), 399413.

Futagami, Koichi, Yuichi Morita, and Akihisa Shibata, "Dynamic Analysis of an Endogenous Growth Model with Public Capital," in Endogenous Growth, ed. by Torben M. Andersen and Karl O. Moene, Basil Blackwell (Oxford: 1993).

Ghosh, Sugata, and Udayan Roy, "Fiscal Policy, Long-Run Growth, and Welfare in a Stock-Flow Model of Public Goods," Canadian Journal of Economics, 37 (August 2004), 742-56.

Glomm, Gerhard, and B. Ravikumar, "Public Investment in Infrastructure in a Simple Growth Model," Journal of Economic Dynamics and Control, 18 (November 1994), 1173-87.

Gómez, Manuel A., "Optimal Fiscal Policy in a Growing Economy with Public Capital," Macroeconomic Dynamics, 8 (September 2004), 419-35.

Hulten, Charles R., "Infrastructure Capital and Economic Growth: How Well you Use it may be more Important than how much you Have," Working Paper No. 5847, National Bureau of Economic Research (December 1996).

Ogaki, Masao, Jonathan Ostry, and Carmen M. Reinhart, "Saving Behavior in Low- and Middle-Income Developing Countries: A Comparison," IMF Staff Papers, 43 (March 1996), 38-71.

Ortigueira, Salvador, "Fiscal Policy in an Endogenous Growth Model with Human Capital Accumulation," Journal of Monetary Economics, 42 (October 1998), 323-55.

Otto, Glenn D., and Graham M. Voss, "Is Public Capital Provision Efficient?," Journal of Monetary Economics, 22 (June 1998), 47-66.

Piras, Romano, "Government Spending Composition in an Endogenous Growth Model with Congestion," Metroeconomica, 52 (February 2001), 121-36. 
Rioja, Felix K., "Roads versus Schooling: Growth Effects of Government Choices," Topics in Macroeconomics, 5 (March 2005), 1-22.

Rioja, Felix K., and Gerhard Glomm, "Populist Budgets and Long Run Growth," unpublished, Indiana University (April 2003).

Rivas, Luis A., "Income Taxes, Spending Composition and Long-Run Growth," European Economic Review, 47 (June 2003), 477-503.

Saghir, Jamal, "Energy and Poverty: Myths, Links, and Policy Issues," Working Note No. 4, Energy and Mining Sector Board, World Bank (May 2005).

Song, Lei L., "Public Capital, Congestion and Private Production in Australia," Working Paper No. 23/02, University of Melbourne (November 2002).

Tsoukis, Chris, and Nigel J. Miller, "Public Services and Endogenous Growth," Journal of Policy Modeling, 25 (April 2003), 297-307.

Turnovsky, Stephen J., "Fiscal Policy in a Growing Economy with Public Capital," Macroeconomic Dynamics, 1 (September 1997), 615-39.

—_ "Fiscal Policy, Elastic Labor Supply, and Endogenous Growth," Journal of Monetary Economics, 45 (February 2000), 185-210.

Turnovsky, Stephen J., and Walter H. Fisher, "Composition of Government Expenditure and its Consequences for Macroeconomic Performance," Journal of Economic Dynamics and Control, 19 (May 1995), 747-86.

UNESCO, Global Education Digest 2004, Unesco Institute for Statistics (Montreal: 2004).

United Nations Millennium Project, Investing in Development: A Practical Plan to Achieve the Millennium Development Goals, Report to the United Nations Secretary General, New York (January 2005).

World Bank, Investing in Infrastructure, World Development Report 1994, Oxford University Press (New York: 1994). 


\section{Figure 1}

Shift in Spending from Education to Infrastructure

(Absolute deviations from baseline, in percent)

— Base case $\quad$...... High infrastructure case $\quad$ - - . High education services case
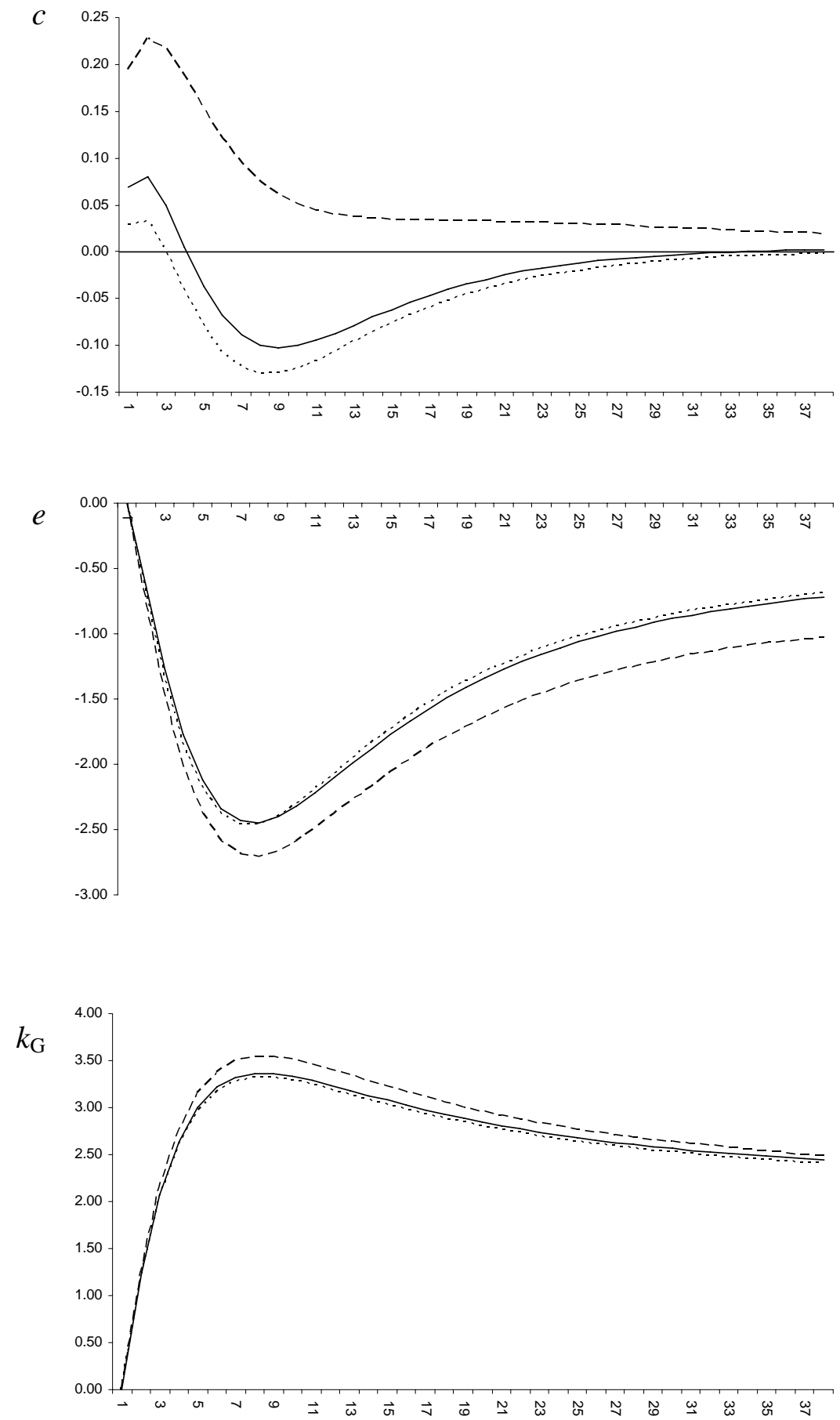